\title{
Interactive comment on "Coarse mode mineral dust size distributions, composition and optical properties from AER-D aircraft measurements over the Tropical Eastern Atlantic" by Claire L. Ryder et al.
}

Claire L. Ryder et al.

c.l.ryder@reading.ac.uk

Received and published: 9 November 2018

The comment was uploaded in the form of a supplement:

https://www.atmos-chem-phys-discuss.net/acp-2018-739/acp-2018-739-AC4-

supplement.pdf 